\title{
The cost of carbon dioxide removal via Direct Air Mineralization of natural rocks: Case studies in Japan \\ COREY A MYERS
}

Waseda University

Presenting Author: corey.a.myers@aoni.waseda.jp

To achieve the goals of the Paris Agreement, implementation of gigatonnes per year of permanent $\mathrm{CO}_{2}$ removal from the atmosphere (so-called, Negative Emissions Technology:NETs, alternatively Carbon Dioxide Removal: CDR) is necessary [1]. The currently dominant CDR methods in policy and modeling discussions are Biomass Energy with $\mathrm{CO}_{2}$ Capture and Storage (BECCS) and Direct Air $\mathrm{CO}_{2}$ Capture with Storage (DACCS). Both BECCS and DACCS rely on the development of a vast infrastructure of $\mathrm{CO}_{2}$ transportation and geological storage. While technically feasible, linking climatic stability to a single $\mathrm{CO}_{2}$ storage method is inherently risky. As a supplemental CDR method, we have previously designed a system that directly removes and stabilizes atmospheric $\mathrm{CO}_{2}$ as magnesium and calcium carbonate minerals via gas-solid reaction with naturally abundant surface rocks; so-called direct air mineralization [2]. We showed that application of direct air mineralization to Japan alone could yield gigatonnes of $\mathrm{CO}_{2}$ removal per year.

Herein we analyze the cost of direct air mineralization for several sites in Japan. We limit our analysis to sites with significant detail in the literature about the mineral composition of the surface rocks. The capital expenditure of land acquisition, site preparation, building construction, on-site renewable energy generation, and the various equipment used for mining, milling, and handling rocks are considered. Operational expenses include supplemental energy purchased from the grid, maintenance and replacement of equipment, and worker salaries. We account for changes in the cost and $\mathrm{CO}_{2}$ intensity of electricity that are projected over the lifetime of a facility.

Our analysis finds that significant variation in the cost per tonne of $\mathrm{CO}_{2}$ removal is due to the mineral composition of the rocks. Rocks that include highly reactive compounds may still yield high costs if the total $\mathrm{CO}_{2}$ mineralization potential of the rocks is low (i.e., the $\mathrm{Ca}$ and $\mathrm{Mg}$ content is small). When applied to appropriate rocks, direct air mineralization operates at a levelized cost of $\mathrm{CO}_{2}$ removal that is well below that of BECCS and DACCS.

[1] IPCC (2018) Summary for policymakers.

[2] Myers and Nakagaki (2020) Environ. Res. Lett. 15, 124018. 